\title{
Achilles Tendinopathy: Current Concepts about the Basic Science and Clinical Treatments
}

\author{
Hong-Yun Li and Ying-Hui Hua \\ Sports Medicine Center of Fudan University, Department of Sports Medicine and Arthroscopy Surgery, \\ Huashan Hospital, Shanghai 200040, China
}

Correspondence should be addressed to Ying-Hui Hua; hua_cosm@aliyun.com

Received 30 June 2016; Accepted 20 September 2016

Academic Editor: Jiang Du

Copyright (C) 2016 H.-Y. Li and Y.-H. Hua. This is an open access article distributed under the Creative Commons Attribution License, which permits unrestricted use, distribution, and reproduction in any medium, provided the original work is properly cited.

\begin{abstract}
Achilles tendinopathy is one of the most frequently ankle and foot overuse injuries, which is a clinical syndrome characterized by the combination of pain, swelling, and impaired performance. The two main categories of Achilles tendinopathy are classified according to anatomical location and broadly include insertional and noninsertional tendinopathy. The etiology of Achilles tendinopathy is multifactorial including both intrinsic and extrinsic factors. Failed healing response and degenerative changes were found in the tendon. The failed healing response includes three different and continuous stages (reactive tendinopathy, tendon disrepair, and degenerative tendinopathy). The histological studies have demonstrated an increased number of tenocytes and concentration of glycosaminoglycans in the ground substance, disorganization and fragmentation of the collagen, and neovascularization. There are variable conservative and surgical treatment options for Achilles tendinopathy. However, there has not been a gold standard of these treatments because of the controversial clinical results between various studies. In the future, new level I researches will be needed to prove the effect of these treatment options.
\end{abstract}

\section{Introduction}

The clinical symptoms of pain, swelling, and impaired physical function of Achilles tendon are common in sports and daily life. Traditionally, many terms have been used to describe the disorders, including tendinitis, tendinosis, and paratenonitis. However, recent histopathological studies have found these disorders as a result of a failed healing response, which may cause degenerative changes in the tendon. The failed healing response includes three different and continuous stages (reactive tendinopathy, tendon disrepair, and degenerative tendinopathy) [1-3]. However, inflammatory response is not found in the three stages. In 1998, Maffulli et al. suggested to use the term tendinopathy in order to describe these intratendinous disorders [4].

The two main categories of Achilles tendinopathy are classified according to anatomical location and broadly include insertional (at the calcaneus-Achilles tendon junction) and noninsertional (2 to $6 \mathrm{~cm}$ proximal to the insertion of the Achilles tendon into the calcaneus) tendinopathy [5].

\section{Epidemiology}

Achilles tendinopathy is one of the most frequently ankle and foot overuse injuries [6]. This disorder is more likely to be found in the individuals who participate in the physical activities such as running and jumping. It may affect $9 \%$ of recreational runners and cause up to $5 \%$ of professional athletes to end their careers [7]. In an epidemiologic investigation of 1394 nonathletes, Achilles tendinopathy was found in $5.6 \%$ of the subjects ( $4 \%$ insertional, $3.6 \%$ noninsertional, and $1.9 \%$ both forms) [8]. In another research, Kvist found that $20 \%$ to $25 \%$ of Achilles tendinopathy patients had insertional disorder, $66 \%$ had noninsertional, and 23\% had either retrocalcaneal bursitis or insertional tendinopathy [9].

Chronic Achilles tendinopathy is more common in older people than in young people. In Kvist's study, among 470 patients who had Achilles tendinopathy, only $25 \%$ of the patients were young athletes and $10 \%$ were younger than 14 years [9]. Moreover, insertional tendinopathy tends to occur in more active persons, whereas noninsertional tendon injury 
tends to occur in older, less active, and overweight persons [10].

\section{Etiology}

The risk factors of Achilles tendinopathy can be divided into intrinsic and extrinsic factors, either alone or combination. Intrinsic factors include biomechanical abnormalities of the lower extremity such as leg length discrepancy hyperpronation, varus deformity of the forefoot, pes cavus and limited mobility of the subtalar joint [10], and systemic conditions such as increasing age [11, 12], inflammatory arthropathies, corticosteroid use, diabetes, hypertension, obesity, gout, hyperostotic conditions [13-16], lipidaemias, aromatase inhibitors, and quinolone antibiotics [17]. Extrinsic factors include excessive mechanical overload and training errors such as increased interval training, abrupt changes in scheduling, excessive hill training, training on hard or sloping surfaces, increased mileage, increased repetitive loading, poor shock absorption, and wedging from uneven wear $[10,15,17]$.

\section{Tendon Anatomy and Physiology}

4.1. Histology and Anatomy. The Achilles tendon originates from the merging of the soleus muscle with the two bellies of the gastrocnemius and it is inserted distally onto the calcaneus. The normal tendon is seen as a fibrillar and generally rounded structure that is white and elastic, because most of them are avascular. Two kinds of cells, tenoblasts and tenocytes, account for 90-95\% of the cellular element of the tendon. The cells in a normal Achilles tendon are well organized. The remaining $5-10 \%$ of cells are chondrocytes at the entheses and a few synovial cells in the synovial tendon sheath [18-20]. The extracellular matrix between the collagen fibers and tenocytes is composed of glycosaminoglycans, glycoproteins, and proteoglycans, whose high hydrophilicity contributes to the elasticity of the tendon $[19,21]$. The tendon is mainly composed of collagen fibers, which make up $90 \%$ of the tendon protein or $70 \%$ to $80 \%$ of the dry weight of the tendon. Type I collagen is the commonest; it forms $95 \%$ of tendon collagen, and most of the collagen fibers are aligned longitudinally [22]. Other types of collagen, such as type III, type V, and type XII, are also important in the tendon [21]. Type III collagen has an important role in the healing and developing process. As type III collagen tends to produce smaller, less organized fibrils, this has implications for the mechanical strength of the tendon. Type V collagen is intercalated into the core of the type I collagen fibril, where it forms a template for fibrillogenesis and modulates fibril growth [23]. Collagen type XII has been postulated to integrate adjacent matrix components due to its ability to bind proteoglycans, fibromodulin, and decorin, while interacting with collagen type I fibrils [24]. Elastin accounts for only about $2 \%$ of the dry mass of tendon and can undergo up to $200 \%$ strain before failure [18]. Collagen forms microfibrils, fibrils, and fibers. A group of fibers constitutes a fascicle. The fascicles unite to form bundles, and they are surrounded by the endotenon, which carries blood vessels, lymphatics, and nerves [20].

The normal blood supply to the tendon is variable between different age and area. The Achilles tendon receives blood supply from three sources: the muscle-tendon junction, the bone-tendon junction, and the length of the tendon. The blood supply to middle portion of the tendon is by way of the surrounding paratenon (the most important blood supply to the tendon) $[25,26]$. The most abundant blood supply zone in the tendon is at the tendon insertion, whereas, in the people who are older than 30 years, the most intensely vascularized zone is at the tendon origin. The area of the tendon approximately 2 to $6 \mathrm{~cm}$ above the insertion into the calcaneus is the least vascularized zone at all ages [26-29], resulting in limited reparative ability at times of stress or injury.

The nerve supply to the tendon comes from the overlying superficial nerves or from nearby deep nerves, the tibial nerve and its branches [30]. The nerves travel along with the blood vessels. Four types of afferent receptors are found either on the surface or in the tendon. The receptors are (a) Ruffini corpuscles, pressure receptor; (b) Vater-Pacinian corpuscles, movement receptor; (c) Golgi tendon organs, mechanoreceptor; and (d) free nerve endings, acting as pain receptors [26]. Golgi organs are the most abundant receptor at the tendon attachments, which can detect pressure and stretching changes in the Achilles tendon [31].

\section{Pathology}

In the Achilles tendinopathy patients, the tendon turns out to be thickened, uneven, and brownish. Histological examination of the affected tissue shows no macrophages, neutrophils, or other inflammatory cells. Therefore, traditional terms tendinitis and tendonitis are inappropriate for designating this tendon disorder [32]. As the histological studies demonstrate an increased number of tenocytes and concentration of glycosaminoglycans in the ground substance, disorganization and fragmentation of the collagen, and neovascularization, the term "tendinopathy" seems preferable. The tenocytes present at the site of degeneration have an irregular shape and a higher rate of apoptosis [10, 32-34]. These tissue changes progress to chronic mucoid and/or lipoid degeneration of the tendon with a variable amount of fibrocartilaginous metaplasia and calcium hydroxyapatite deposits [17, 35]. In chronic Achilles tendinopathy, major molecular changes include increased expression of type III collagen, fibronectin, tenascin C, aggrecan, and biglycan. These changes are consistent with repair, but they might also be an adaptive response to changes in mechanical loading because repeated minor strain is thought to be the major precipitating factor in tendinopathy [36].

Healthy tendons are relatively avascular. Neovascularization, a descriptive term for the appearance of abnormal vessels, is one feature of Achilles tendinopathy [37, 38]. Neovascularization and the accompanying neonerves have been hypothesized to be the source of pain in chronic midportion Achilles tendinopathy [3, 39-43]. Moreover, postcapillary venous filling pressures are increased at both the midportion 
Achilles tendon and the paratendon tissues. However, the tissue oxygen saturation in tendon does not show any difference between Achilles tendinopathy and normal tendon tissue [44]. Moreover, mechanoreceptors and nerverelated components such as glutamate $\mathrm{N}$-methyl-D-aspartate (NMDA) receptors are present in association with blood vessels in tendinopathic tendons [45-47]. In a rabbit model of tendinopathy, the increased expression of angiogenesis factor (vascular endothelial growth factor (VEGF)) was detected and the pattern of vascularity showed an increase in the number of tendon blood vessels [48].

5.1. Natural Healing of Tendinopathy. Tendon repair involves a sequence of three phases. The first inflammatory phase lasts a few days. Erythrocytes and inflammatory cell migrate to the injury site within the first $24 \mathrm{~h}$. Vasoactive and chemotactic factors are released with increased vascular permeability, initiation of angiogenesis, proliferation of tenocyte, and production of collagen fiber [49]. After a few days, the proliferative phase begins. Synthesis of type III collagen reaches a peak during this stage, which lasts for a few weeks [49]. Water content and glycosaminoglycan concentrations remain high during this stage. Tendon repair coincides with tenocyte proliferation in the epitenon and endotenon, as well as in the tendon sheath [17]. Finally, after approximately 6 weeks, the modeling stage starts. The healing tissue is resized and reshaped [49]. Syntheses of cellularity, collagen, and glycosaminoglycan are decreased. This remodeling phase starts with a fibrous consolidation process. In this period, the repair tissue changes from cellular to fibrous and the collagen fibers align along the direction of the loads applied to the tendon. Then, after the tenth postinjury week, the maturation phase occurs, with gradual change of fibrous tissue to scarlike tendon tissue over the course of one year [46].

Matrix metalloproteinases (MMPs) are a family of proteolytic enzymes, which are classified according to their substrate and primary structure. Previous studies indicated that the MMPs are important in regulating the extracellular matrix network remodeling, and their amounts are changing during Achilles tendon healing process [46].

The quality of the tissue is weakened because of the abnormal healing process, with disordered proliferation of tenocytes, degeneration change of tendon cells, disruption of collagen fibers, and eventually increasing of noncollagenous matrix. If the source of the tendon injury persists, the area of degeneration or the tear may persist or worsen over time [20].

The sources of pain in Achilles tendinopathy are very complicated. The pain may originate from multiple factors. Increased production of prostaglandins (PGs) in matrix, neovascularization in tendon body, tenocyte changes in structure and function, and metabolites changes in tendinopathy are thought to be the sources of pain [47]. Chemical irritants, including cytokines (tumour necrosis factor-alpha (TNFa) and interleukin- (IL-) $1 \mathrm{~b}$ ), signalling molecules $\left(\mathrm{Ca}^{2+}\right.$, adenosine triphosphate (ATP)), neuropeptides (substance P (SP), neuropeptide $\mathrm{Y}$ ), and neurotransmitters such as glutamate, have been found to be elevated in tendinopathy and proposed as causing pain $[47,48]$. Recent research indicated that the nonneuronal cholinergic system also has been implicated as a factor of pain in chronic tendinopathy [49].

\section{Treatment}

6.1. Nonoperative Management. In the acute phase, initial rest is the most important. The use of braces and immobilization with a cast or pneumatic walking boot are combined with modified activity [10]. Immobilization is frequently used in the acute setting to control exacerbating factors, but prolonged immobilization should be avoided. Modification of training regimes and specific exercises are necessary. Most patients will be able to return to previous activities. Orthotics may be helpful alongside other modalities of treatment if there is an identifiable malalignment, whereas braces or splints do not appear to improve outcomes in Achilles tendinopathy [50]. A graduated shoe raise or heel lift can alleviate pressure on the insertion by plantar flexing the heel. Hindfoot malalignment associated with insertional disorders can be corrected by insoles, if it is thought to be a provocative factor [51].

Ultrasound is a common prescribed program of physical therapy. In animal studies, ultrasound could stimulate collagen synthesis in tendon fibroblasts and cell division during the period of rapid cell proliferation [52]. Therapeutic ultrasound has been shown to reduce the swelling in the acute inflammatory phase of soft-tissue disorders, relieve pain, and increase function in patients with chronic tendon injuries and may enhance tendon healing $[53,54]$. However, due to a lack of new, high quality data on the effect of ultrasound on Achilles tendinopathy, the evidence remains insufficient to support its clinical use $[55,56]$.

Low level laser therapy (LLLT) could reduce the expression of proinflammatory markers such as IL- 6 and TNF- $\alpha$ in gene level [57]. In the cellular level, LLLT may increase collagen production [58], stimulate tenocyte proliferation [59], downregulate MMPs, decrease the capillary flow of neovascularization, and finally preserve the resistance and elasticity of tendon $[60,61]$. In a placebo-controlled, doubleblind, prospective study of twenty-five patients with a total of forty-one digital flexor tendon repairs, laser therapy could reduce postoperative edema but did not relieve the pain and increase the grip strength or functional results compared with those in control group [62]. Another randomized controlled clinical study indicated that LLLT was not used in treating midportion Achilles tendinopathy [63]. A metaanalysis indicated that LLLT could potentially be effective in treatment of tendinopathy when recommended dosages were used [64]. In the future, new, high quality researches will be needed to prove the effect of LLLT in treatment of Achilles tendinopathy.

The scientific basis of NSAIDs used in chronic tendinopathy is questionable, because the histological examination in the tendinopathic tissue shows no inflammatory cells [21]. The benefits of NSAIDs use are reliving pain in the acute phase and reducing the possibility of leg stiffness [65]. However, there are some studies that indicated that the NSAIDs may inhibit tendon cell migration and proliferation 
and impair tendon healing [66]. Some authors believed that NSAIDs had little or no effect on the clinical outcome $[5,67]$.

Corticosteroid injections are reported to reduce pain and swelling and improve the ultrasound appearance of the tendon. The mechanism behind any positive effect of local steroids on chronic Achilles tendinopathy remains unclear. Some authors have hypothesized that any beneficial effects of corticosteroids in this condition are owed to other local steroid effects rather than suppression of inflammation, including lyses of tendon and peritendon adhesions or alteration of the function of pain generating nociceptor in the region [68]. Corticosteroid injections may have some benefit in the short term, but adverse effects were reported in up to $82 \%$ of corticosteroid trials [69]; these include tendon atrophy [69], tendon rupture [70], and decreased tendon strength [71, 72]. Corticosteroid injections could cause vasoconstriction through prostacyclin and adrenoceptors and inhibit nitric oxide synthase, which may be the source of adverse effects [20]. Any possible benefit of corticosteroid injection appears to be outweighed by potential risks. Overall, the evidence to support the injection of corticosteroid in or around the Achilles tendon is insufficient.

Many studies and systematic reviews have found that eccentric exercises are beneficial in the early treatment of noninsertional Achilles tendinopathy [56, 68, 73], but the mechanism of how this exercise works is poorly understood. Theoretically, the reasons of eccentric exercise in reducing pain and improving healing process include more rapid strengthening of the calf muscle, stiffening and lengthening of the myotendinous unit, and decreasing of neovascularization in the tendon [68]. The tensile force generated within the tendon during the exercise temporarily ceases blood flow through the neovessels. With repetition over time, the neovessels are obliterated, along with their associated pain receptors, which lead to the relief of symptoms [55]. The potential harms of eccentric exercise include delayedonset muscle soreness, exacerbation of the tendinopathy, and muscle injuries [50]. This injury may increase in subjects who are unaccustomed to exercises and if sufficient recovery periods are not allowed. Muscle injuries often occur when athletes are fatigued and strength recovery may take up to 24 hours after exercise [73]. Therefore, the exercise should be taught and monitored by a health professional, such as a physiotherapist or sports medicine physician, capable of ensuring correct biomechanics and of supervising the gradual increase of tendon loading [50].

Conflicting results have been reported for extracorporeal shockwave therapy (ESWT) [20]. How ESWT works is still poorly understood, but it is known to cause selective dysfunction of sensory unmyelinated nerve fibers, alteration in the dorsal root ganglia, and cavitation in interstitial and extracellular disruption, which could promote the healing response [74]. Recently, an in vivo study found that mechanical stimulus provided by ESWT might aid the initiation of tendon regeneration in tendinopathy by promoting proinflammatory and catabolic processes that are associated with removing damaged matrix constituents [75]. In recent research, series randomized placebo-controlled trials have confirmed the high evidence of efficacy of ESWT in chronic
Achilles tendinopathy [74]. However, the most effective dose and duration of ESWT are still unknown.

The introduction of platelet-rich plasma (PRP) at the site of tendon injury is thought to facilitate healing because it contains several different growth factors and other cytokines that can stimulate healing of soft tissue [55]. Animal studies indicated that PRP could increase the expression of collagen types I and III and vascular endothelial growth factor and improve the healing and remodeling process of the tendon $[76,77]$. A lot of studies demonstrating improved tendon healing using PRP compared with controls, but controversial clinical results exist when using PRP to treat Achilles tendinopathy [78-84]. Ultrasound guidance allows injected PRP into the tendon with great accuracy $[79,84]$. However, the evidence to support the use of PRP in the management of Achilles tendinopathy is insufficient and level I, controlled, randomized studies are still needed in the future researches.

Intratendinous hyperosmolar dextrose (prolotherapy) is thought to produce a local inflammatory response and increase in tendon strength. Clinical results indicated that intratendinous injections of hyperosmolar dextrose could reduce the pain at rest and during tendon-loading activities in patients with chronic of the Achilles tendinopathy $[85,86]$. Moreover, after injection of dextrose, there were reductions in the size and severity of hypoechoic regions and intratendinous tears and improvements in neovascularity [86].

Nitric oxide is a small-free radical generated by a family of enzymes, the nitric oxide synthases. It can induce apoptosis in inflammatory cells and cause angiogenesis and vasodilation. Moreover, oxygen free radicals can stimulate fibroblast proliferation [87]. Nitric oxide can enhance tendon healing. Inhibition of nitric oxide synthase can reduce healing process, which resulted in a decreased crosssectional area and reduced failure load [48]. Theoretical, topical glyceryl trinitrate (GTN) application could increase local tissue nitric oxide concentrations, which are believed to improve fibroblast function and wound healing [68]. Acute GTN facilitates capillary venous outflow in painful Achilles tendons. However, in another study, capillary bloodflow and tendon oxygenation remain unchanged following GTN application [88]. A randomized double-blind placebocontrolled study demonstrated improvements in symptoms using GTN patches [89]. Another randomized controlled trial found no difference between groups in scores between the two groups for pain or disability. Moreover, there has not appeared to be any histological or immunohistochemical change between groups [90].

Cryotherapy might play a role in reducing the increased capillary blood flow in Achilles tendinopathy, reducing the metabolic rate of the tendon and applying for relief of pain [91, 92]. However, recent evidence in upper limb tendinopathy indicated that the addition of ice did not offer any advantage over an exercise program consisting of eccentric and static stretching exercises [93].

The sclerosing agent that selectively targets the vascular may cause thrombosis of the vessel. As the concomitant sensory nerves have been implicated as possible pain generators, to destroy local nerves adjacent to neovessels may decrease pain [55]. As vessel number has been shown to 
correlate with tendon thickness, treatment that decreases vessel number is likely to also affect the tendon thickness. Moreover, the sclerosing agent injected at multiple sites around the tendon and neovessels initiates a local inflammatory response, which induces a proliferation of fibroblasts and synthesis of collagen. Therefore, a stronger, more organized tendon could be produced [52]. Early reports using sclerosing agent injected under Doppler ultrasound guidance into the abnormal vessels on the ventral aspect of the Achilles tendon demonstrated significant improvements in pain and function scores $[54,94]$. However, due to the conflicting results, high quality evidence to make a recommendation for sclerosing injections is needed.

Deep friction massage (DFM) and tendon mobilization may also be helpful in the treatment of Achilles tendinopathy. DFM has been advocated for tendinopathy and paratendinopathy. Friction has been shown to increase protein output of tendon cells [95]. In combination with stretching, deep friction massage helps to restore tissue elasticity and reduce the strain in the muscle-tendon unit [52, 95]. Future randomized comparison studies are necessary to compare DFM in isolation with other modes of treatment.

Aprotinin is a broad spectrum serine protease inhibitor capable of blocking trypsin, plasmin, kallikrein, and a range of MMPs [96]. Most previous studies using Aprotinin injection in the management of Achilles tendinopathy showed a trend towards improved clinical results $[97,98]$. The major potential negative of using Aprotinin is the side effect of allergy [51], but the allergic reactions can be reduced by minimizing repeat injections and recommending a delay of at least 6 weeks between injections [96].

\section{Surgical Treatment}

7.1. Noninsertional Achilles Tendinopathy. The goal of surgery is to resect degenerative tissue, stimulate tendon healing by means of controlled, low-grade trauma and/or augment the Achilles tendon with grafts. It has been suggested that noninvasive treatment should be tried for at least 4 months prior to operative interventions [10]. Conventional surgical treatment has consisted of open release of adhesions with or without resection of the paratenon. If $>50 \%$ of the tendon has been debrided, augmentation or reconstruction is recommended [10].

Several operative treatments include percutaneous longitudinal tenotomies, minimally invasive tendon stripping, open tenosynovectomies, open debridement and tubularization, and tendon augmentation with flexor hallucis longus (FHL). Long-term results of operative interventions are promising but need more fair evidence to support the clinical use.

Complications are common in surgical procedure. In a large series of 432 consecutive patients, Paavola et al. reported wound necrosis in 3\%, superficial infection in $2.5 \%$, and sural nerve injury in $1 \%$, with further complications including haematoma, seroma, and thrombosis. Therefore, the overall complication rate was $11 \%$ and reoperation rate was 3\% [99].
7.2. Insertional Achilles Tendinopathy. Patients who do not respond to conservative treatment may need operative manage. No consensus exists regarding the duration before surgery, though most clinicians consider 3 to 6 months the minimum time necessary to evaluate the effect of conservative treatment [100].

The operative strategy for insertional Achilles tendinopathy is removal of the degenerative tendon and associated calcification, excision of the inflamed retrocalcaneal bursa, resection of the prominent posterior calcaneal prominence, reattachment of the insertion as required, and/or augmentation of the tendo-Achilles with a tendon transfer/graft [101, 102]. Calcaneoplasty and resection of the retrocalcaneal bursa can be performed endoscopically [102].

Biomechanical and clinical data suggest that $50 \%$ of the tendon attachment can be safely debrided without compromise of the insertion strength or risk of rerupture. When greater than $50 \%$ of the Achilles tendon is detached from the calcaneus, suture anchors are recommended to reattach the residual tendon. With extensive insertional, Achilles tendon disease and/or when greater than $75 \%$ of the tendon is excised, augmentation with local tissue, such as the flexor hallucis longus tendon and semitendinosus tendon, is advisable [102].

\section{Conclusion}

Achilles tendinopathy is a clinical syndrome characterized by the combination of pain, swelling, and impaired performance. The etiology of Achilles tendinopathy is multifactorial including intrinsic and extrinsic factors. The histological studies demonstrate an increased number of tenocytes and concentration of glycosaminoglycans in the ground substance, disorganization and fragmentation of the collagen, and neovascularization. The sources of pain in Achilles tendinopathy are very complicated. The pain may originate from multiple factors. There are variable conservative and surgical treatment options for Achilles tendinopathy. However, there is no gold standard of the treatments because of the controversial clinical results between various studies. In the future, more new level I researches are needed to prove the effect of these treatment options.

\section{Competing Interests}

The authors declare that there are no competing interests regarding the publication of this paper.

\section{References}

[1] M. Abate, K. G. Silbernagel, C. Siljeholm et al., "Pathogenesis of tendinopathies: inflammation or degeneration?" Arthritis Research \& Therapy, vol. 11, no. 3, p. 235, 2009.

[2] J. L. Cook and C. R. Purdam, "Is tendon pathology a continuum? A pathology model to explain the clinical presentation of load-induced tendinopathy," British Journal of Sports Medicine, vol. 43, no. 6, pp. 409-416, 2009. 
[3] U. G. Longo, M. Ronga, and N. Maffulli, "Achilles tendinopathy," Sports Medicine and Arthroscopy Review, vol. 17, no. 2, pp. 112126, 2009.

[4] N. Maffulli, K. M. Khan, and G. Puddu, "Overuse tendon conditions: time to change a confusing terminology," Arthroscopy, vol. 14 , no. 8, pp. 840-843, 1998.

[5] L. C. Almekinders and J. D. Temple, "Etiology, diagnosis, and treatment of tendonitis: an analysis of the literature," Medicine \& Science in Sports \& Exercise, vol. 30, no. 8, pp. 1183-1190, 1998.

[6] S. Sobhani, R. Dekker, K. Postema, and P. U. Dijkstra, "Epidemiology of ankle and foot overuse injuries in sports: a systematic review," Scandinavian Journal of Medicine \& Science in Sports, vol. 23, no. 6, pp. 669-686, 2013.

[7] J. Lysholm and J. Wiklander, "Injuries in runners," American Journal of Sports Medicine, vol. 15, no. 2, pp. 168-171, 1987.

[8] U. Waldecker, G. Hofmann, and S. Drewitz, "Epidemiologic investigation of 1394 feet: coincidence of hindfoot malalignment and Achilles tendon disorders," Foot and Ankle Surgery, vol. 18, no. 2, pp. 119-123, 2012.

[9] M. Kvist, "Achilles tendon injuries in athletes," Annales Chirurgiae et Gynaecologiae, vol. 80, no. 2, pp. 188-201, 1991.

[10] T. A. Irwin, "Current concepts review: insertional Achilles tendinopathy," Foot and Ankle International, vol. 31, no. 10, pp. 933-939, 2010.

[11] R. Strocchi, V. De Pasquale, S. Guizzardi et al., "Human achilles tendon: morphological and morphometric variations as a function of age," Foot and Ankle, vol. 12, no. 2, pp. 100-104, 1991.

[12] D. J. Tuite, P. A. F. H. Renström, and M. O’Brien, “The aging tendon," Scandinavian Journal of Medicine and Science in Sports, vol. 7, no. 2, pp. 72-77, 1997.

[13] M. Fahlström, R. Lorentzon, and H. Alfredson, "Painful conditions in the Achilles tendon region: a common problem in middle-aged competitive badminton players," Knee Surgery, Sports Traumatology, Arthroscopy, vol. 10, no. 1, pp. 57-60, 2002.

[14] G. B. Holmes and J. Lin, "Etiologic factors associated with symptomatic achilles tendinopathy," Foot and Ankle International, vol. 27, no. 11, pp. 952-959, 2006.

[15] B. Murtaugh and J. M. Ihm, "Eccentric training for the treatment of tendinopathies," Current Sports Medicine Reports, vol. 12, no. 3, pp. 175-182, 2013.

[16] M. Paavola, P. Kannus, T. A. H. Järvinen, K. Khan, L. Józsa, and M. Järvinen, "Achilles tendinopathy," Journal of Bone and Joint Surgery A, vol. 84, no. 11, pp. 2062-2076, 2002.

[17] T. Kirchgesner, A. Larbi, P. Omoumi et al., "Drug-induced tendinopathy: from physiology to clinical applications," Joint Bone Spine, vol. 81, no. 6, pp. 485-492, 2014.

[18] E. Ippolito, P. G. Natali, F. Postacchini, L. Accinni, and C. De Martino, "Morphological, immunochemical, and biochemical study of rabbit Achilles tendon at various ages," The Journal of Bone \& Joint Surgery-American Volume, vol. 62, no. 4, pp. 583598, 1980.

[19] P. Kannus and L. Józsa, "Histopathological changes preceding spontaneous rupture of a tendon: a controlled study of 891 patients," The Journal of Bone and Joint Surgery A, vol. 73, no. 10, pp. 1507-1525, 1991.

[20] A. J. Roche and J. D. F. Calder, "Achilles tendinopathy: a review of the current concepts of treatment," The Bone \& Joint Journal, vol. 95, no. 10, pp. 1299-1307, 2013.

[21] W. J. Ribbans and M. Collins, "Pathology of the tendo Achillis: do our genes contribute?" The Journal of Bone and Joint Surgery $B$, vol. 95, no. 3, pp. 305-313, 2013.
[22] N. Maffulli, P. M. Binfield, and J. B. King, “Tendon problems in athletic individuals," The Journal of Bone \& Joint SurgeryAmerican Volume, vol. 80, no. 1, pp. 142-144, 1998.

[23] D. T. Kirkendall and W. E. Garrett, "Function and biomechanics of tendons," Scandinavian Journal of Medicine \& Science in Sports, vol. 7, no. 2, pp. 62-66, 1997.

[24] M. O'Brien, "The anatomy of the achilles tendon," Foot and Ankle Clinics, vol. 10, no. 2, pp. 225-238, 2005.

[25] I. M. Ahmed, M. Lagopoulos, P. McConnell, R. W. Soames, and G. K. Sefton, "Blood supply of the achilles tendon," Journal of Orthopaedic Research, vol. 16, no. 5, pp. 591-596, 1998.

[26] J. M. McShane, B. Ostick, and F. McCabe, "Noninsertional Achilles tendinopathy: pathology and management," Current Sports Medicine Reports, vol. 6, no. 5, pp. 288-292, 2007.

[27] V. Niculescu and P. Matusz, "The clinical importance of the calcaneal tendon vasculature (tendo calcaneus)," Morphologie et Embryologie, vol. 34, no. 1, pp. 5-8, 1988.

[28] M. O’Brien, "Functional anatomy and physiology of tendons," Clinics in Sports Medicine, vol. 11, no. 3, pp. 505-520, 1992.

[29] S. M. Lephart, D. M. Pincivero, J. L. Giraldo, and F. H. Fu, “The role of proprioception in the management and rehabilitation of athletic injuries," American Journal of Sports Medicine, vol. 25, no. 1, pp. 130-137, 1997.

[30] C. J. Pearce, M. Ismail, and J. D. Calder, "Is apoptosis the cause of noninsertional achilles tendinopathy?" The American Journal of Sports Medicine, vol. 37, no. 12, pp. 2440-2444, 2009.

[31] B. Dallaudière, M. Lempicki, L. Pesquer et al., "Efficacy of intra-tendinous injection of platelet-rich plasma in treating tendinosis: comprehensive assessment of a rat model," European Radiology, vol. 23, no. 10, pp. 2830-2837, 2013.

[32] J. G. P. Williams, "Achilles tendon lesions in sport," Sports Medicine, vol. 16, no. 3, pp. 216-220, 1993.

[33] J. S. Yu, J. E. Popp, C. C. Kaeding, and J. Lucas, "Correlation of MR imaging and pathologic findings in athletes undergoing surgery for chronic patellar tendinitis," American Journal of Roentgenology, vol. 165, no. 1, pp. 115-118, 1995.

[34] H. Alfredson, D. Bjur, K. Thorsen, and R. Lorentzon, "High intratendinous lactate levels in painful chronic Achilles tendinosis. An investigation using microdialysis technique," Journal of Orthopaedic Research, vol. 20, no. 5, pp. 934-938, 2002.

[35] K. Knobloch, "The role of tendon microcirculation in Achilles and patellar tendinopathy," Journal of Orthopaedic Surgery and Research, vol. 3, no. 1, article 18, 2008.

[36] D. Kader, A. Saxena, T. Movin, and N. Maffulli, "Achilles tendinopathy: some aspects of basic science and clinical management," British Journal of Sports Medicine, vol. 36, no. 4, pp. 239-249, 2002.

[37] P. Sharma and N. Maffulli, "Understanding and managing Achilles tendinopathy," British Journal of Hospital Medicine, vol. 67, no. 2, pp. 64-67, 2006.

[38] P. Sharma and N. Maffulli, "Tendinopathy and tendon injury: the future," Disability and Rehabilitation, vol. 30, no. 20-22, pp. 1733-1745, 2008.

[39] A. M. Vora, M. S. Myerson, F. Oliva, and N. Maffulli, "Tendinopathy of the main body of the achilles tendon," Foot and Ankle Clinics, vol. 10, no. 2, pp. 293-308, 2005.

[40] M. S. Zafar, A. Mahmood, and N. Maffulli, "Basic science and clinical aspects of Achilles tendinopathy," Sports Medicine and Arthroscopy Review, vol. 17, no. 3, pp. 190-197, 2009.

[41] K. Knobloch, R. Kraemer, A. Lichtenberg et al., "Achilles tendon and paratendon microcirculation in midportion and 
insertional tendinopathy in athletes," The American Journal of Sports Medicine, vol. 34, no. 1, pp. 92-97, 2006.

[42] H. Alfredson, K. Thorsen, and R. Lorentzon, "In situ microdialysis in tendon tissue: high levels of glutamate, but not prostaglandin E2 in chronic Achilles tendon pain," Knee Surgery, Sports Traumatology, Arthroscopy, vol. 7, no. 6, pp. 378381, 1999.

[43] G. Andersson, P. Danielson, H. Alfredson, and S. Forsgren, "Nerve-related characteristics of ventral paratendinous tissue in chronic Achilles tendinosis," Knee Surgery, Sports Traumatology, Arthroscopy, vol. 15, no. 10, pp. 1272-1279, 2007.

[44] C. Spang, V. M. Harandi, H. Alfredson et al., "Marked innervation but also signs of nerve degeneration in between the Achilles and plantaris tendons and presence of innervation within the plantaris tendon in midportion Achilles tendinopathy," Journal of Musculoskeletal \& Neuronal Interactions, vol. 15, no. 2, pp. 197-206, 2015.

[45] G. Andersson, S. Forsgren, A. Scott et al., "Tenocyte hypercellularity and vascular proliferation in a rabbit model of tendinopathy: contralateral effects suggest the involvement of central neuronal mechanisms," British Journal of Sports Medicine, vol. 45, no. 5, pp. 399-406, 2011.

[46] P. Sharma and N. Maffulli, "Biology of tendon injury: healing, modeling and remodeling," Journal of Musculoskeletal Neuronal Interactions, vol. 6, no. 2, pp. 181-190, 2006.

[47] E. Rio, L. Moseley, C. Purdam et al., "The pain of tendinopathy: physiological or pathophysiological?” Sports Medicine, vol. 44, no. 1, pp. 9-23, 2014.

[48] P. Sharma and N. Maffulli, "Tendon injury and tendinopathy: healing and repair," The Journal of Bone and Joint Surgery A, vol. 87, no. 1, pp. 187-202, 2005.

[49] S. Forsgren, H. Alfredson, and G. Andersson, "Further proof of the existence of a non-neuronal cholinergic system in the human Achilles tendon: presence of the AChR $\alpha 7$ receptor in tendon cells and cells in the peritendinous tissue," International Immunopharmacology, vol. 29, no. 1, pp. 195-200, 2015.

[50] A. Scott, E. Huisman, and K. Khan, "Conservative treatment of chronic Achilles tendinopathy," CMAJ: Canadian Medical Association journal, vol. 183, no. 10, pp. 1159-1165, 2011.

[51] N. J. Rukin and N. Maffulli, "Systemic allergic reactions to aprotinin injection around the Achilles tendon," Journal of Science and Medicine in Sport, vol. 10, no. 5, pp. 320-322, 2007.

[52] J. D. Rompe, J. P. Furia, and N. Maffulli, "Mid-portion Achilles tendinopathy-current options for treatment," Disability and Rehabilitation, vol. 30, no. 20-22, pp. 1666-1676, 2008.

[53] T. M. Best, B. Moore, P. Jarit, C. T. Moorman, and G. K. Lewis, "Sustained acoustic medicine: wearable, long duration ultrasonic therapy for the treatment of tendinopathy," The Physician and Sportsmedicine, vol. 43, no. 4, pp. 366-374, 2015.

[54] L. Willberg, K. Sunding, L. Öhberg, M. Forssblad, M. Fahlström, and H. Alfredson, "Sclerosing injections to treat midportion Achilles tendinosis: a randomised controlled study evaluating two different concentrations of Polidocanol," Knee Surgery, Sports Traumatology, Arthroscopy, vol. 16, no. 9, pp. 859-864, 2008.

[55] X. F. Courville, M. P. Coe, and P. J. Hecht, "Current concepts review: noninsertional Achilles tendinopathy," Foot and Ankle International, vol. 30, no. 11, pp. 1132-1142, 2009.

[56] V. Rowe, S. Hemmings, C. Barton, P. Malliaras, N. Maffulli, and D. Morrissey, "Conservative management of midportion achilles tendinopathy: a mixed methods study, integrating systematic review and clinical reasoning," Sports Medicine, vol. 42, no. 11, pp. 941-967, 2012.

[57] R. Torres-Silva, R. A. B. Lopes-Martins, J. M. Bjordal et al., "The low level laser therapy (LLLT) operating in $660 \mathrm{~nm}$ reduce gene expression of inflammatory mediators in the experimental model of collagenase-induced rat tendinitis," Lasers in Medical Science, vol. 30, no. 7, pp. 1985-1990, 2014.

[58] M. Xavier, R. A. De Souza, V. A. Pires et al., "Low-level lightemitting diode therapy increases mRNA expressions of IL-10 and type I and III collagens on Achilles tendinitis in rats," Lasers in Medical Science, vol. 29, no. 1, pp. 85-90, 2014.

[59] W.-C. Tsai, J.-W. Cheng, J.-L. Chen et al., "Low-level laser irradiation stimulates tenocyte proliferation in association with increased NO synthesis and upregulation of PCNA and cyclins," Lasers in Medical Science, vol. 29, no. 4, pp. 1377-1384, 2014.

[60] R. L. Marcos, G. Arnold, V. Magnenet, R. Rahouadj, J. Magdalou, and R. Á. B. Lopes-Martins, "Biomechanical and biochemical protective effect of low-level laser therapy for Achilles tendinitis," Journal of the Mechanical Behavior of Biomedical Materials, vol. 29, pp. 272-285, 2014.

[61] R. L. Marcos, E. C. P. Leal-Junior, G. Arnold et al., "Low-level laser therapy in collagenase-induced Achilles tendinitis in rats: analyses of biochemical and biomechanical aspects," Journal of Orthopaedic Research, vol. 30, no. 12, pp. 1945-1951, 2012.

[62] N. Özkan, L. Altan, Ü. Bingöl, S. Akin, and M. Yurtkuran, "Investigation of the supplementary effect of GaAs laser therapy on the rehabilitation of human digital flexor tendons," Journal of Clinical Laser Medicine \& Surgery, vol. 22, no. 2, pp. 105-110, 2004.

[63] S. Tumilty, S. McDonough, D. A. Hurley, and G. D. Baxter, "Clinical effectiveness of low-level laser therapy as an adjunct to eccentric exercise for the treatment of Achilles' tendinopathy: a randomized controlled trial," Archives of Physical Medicine and Rehabilitation, vol. 93, no. 5, pp. 733-739, 2012.

[64] S. Tumilty, J. Munn, S. McDonough, D. A. Hurley, J. R. Basford, and G. D. Baxter, "Low level laser treatment of tendinopathy: a systematic review with meta-analysis," Photomedicine and Laser Surgery, vol. 28, no. 1, pp. 3-16, 2010.

[65] J. Maquirriain and A. Kokalj, "Management of acute Achilles tendinopathy: effect of etoricoxib on pain control and leg stiffness," Georgian Medical News, no. 222, pp. 36-43, 2013.

[66] W.-C. Tsai, C.-C. Hsu, S.-W. Chou, C.-Y. Chung, J. Chen, and J.-H. Pang, "Effects of celecoxib on migration, proliferation and collagen expression of tendon cells," Connective Tissue Research, vol. 48, no. 1, pp. 46-51, 2007.

[67] M. Åström and N. Westlin, "No effect of piroxicam on achilles tendinopathy: a randomized study of 70 patients," Acta Orthopaedica Scandinavica, vol. 63, no. 6, pp. 631-634, 1992.

[68] R. A. Magnussen, W. R. Dunn, and A. B. Thomson, "Nonoperative treatment of midportion achilles tendinopathy: a systematic review," Clinical Journal of Sport Medicine, vol. 19, no. 1, pp. 5464, 2009.

[69] L. Hart, "Corticosteroid and other injections in the management of tendinopathies: a review," Clinical Journal of Sport Medicine, vol. 21, no. 6, pp. 540-541, 2011.

[70] R. S. Kearney, N. Parsons, D. Metcalfe, and M. L. Costa, "Injection therapies for Achilles tendinopathy," The Cochrane Database of Systematic Reviews, vol. 5, Article ID CD010960, 2015.

[71] B. T. Haraldsson, H. Langberg, P. Aagaard et al., "Corticosteroids reduce the tensile strength of isolated collagen fascicles," 
The American Journal of Sports Medicine, vol. 34, no. 12, pp. 1992-1997, 2006.

[72] R. Hugate, J. Pennypacker, M. Saunders, and P. Juliano, “The effects of intratendinous and retrocalcaneal intrabursal injections of corticosteroid on the biomechanical properties of rabbit Achilles tendons," The Journal of Bone \& Joint SurgeryAmerican Volume, vol. 86, no. 4, pp. 794-801, 2004.

[73] A. Meyer, S. Tumilty, and G. D. Baxter, "Eccentric exercise protocols for chronic non-insertional Achilles tendinopathy: how much is enough?" Scandinavian Journal of Medicine and Science in Sports, vol. 19, no. 5, pp. 609-615, 2009.

[74] L. Gerdesmeyer, R. Mittermayr, M. Fuerst et al., "Current evidence of extracorporeal shock wave therapy in chronic Achilles tendinopathy," International Journal of Surgery, vol. 24, pp. 154-159, 2015.

[75] C. M. Waugh, D. Morrissey, E. Jones, G. P. Riley, H. Langberg, and H. R. C. Screen, "In vivo biological response to extracorporeal shockwave therapy in human tendinopathy," European Cells and Materials, vol. 29, pp. 268-280, 2015.

[76] J. C. González, C. López, M. E. Álvarez, J. E. Pérez, and J. U. Carmona, "Autologous leukocyte-reduced platelet-rich plasma therapy for Achilles tendinopathy induced by collagenase in a rabbit model," Scientific Reports, vol. 6, article 19623, 2016.

[77] J.-F. Kaux, P. Drion, J. L. Croisier, and J. M. Crielaard, "Tendinopathies and platelet-rich plasma (PRP): from preclinical experiments to therapeutic use," Journal of Stem Cells and Regenerative Medicine, vol. 11, no. 1, pp. P7-P17, 2015.

[78] B. Di Matteo, G. Filardo, E. Kon, and M. Marcacci, "Plateletrich plasma: evidence for the treatment of patellar and Achilles tendinopathy-a systematic review," Musculoskeletal Surgery, vol. 99, no. 1, pp. 1-9, 2015.

[79] G. Ferrero, E. Fabbro, D. Orlandi et al., "Ultrasound-guided injection of platelet-rich plasma in chronic Achilles and patellar tendinopathy," Journal of Ultrasound, vol. 15, no. 4, pp. 260-266, 2012.

[80] G. Filardo, E. Kon, B. Di Matteo et al., "Platelet-rich plasma injections for the treatment of refractory Achilles tendinopathy: results at 4 years," Blood Transfusion, vol. 12, no. 4, pp. 533-540, 2014.

[81] M. Guelfi, A. Pantalone, D. Vanni, M. Abate, M. G. B. Guelfi, and V. Salini, "Long-term beneficial effects of platelet-rich plasma for non-insertional Achilles tendinopathy," Foot and Ankle Surgery, vol. 21, no. 3, pp. 178-181, 2015.

[82] C. D. Murawski, N. A. Smyth, H. Newman, and J. G. Kennedy, "A single platelet-rich plasma injection for chronic midsubstance Achilles tendinopathy: a retrospective preliminary analysis," Foot and Ankle Specialist, vol. 7, no. 5, pp. 372-376, 2014.

[83] V. Salini, D. Vanni, A. Pantalone, and M. Abate, "Platelet rich plasma therapy in non-insertional Achilles tendinopathy: the efficacy is reduced in 60-years old people compared to young and middle-age individuals," Frontiers in Aging Neuroscience, vol. 7, article 228, 2015.

[84] K. Mautner, R. E. Colberg, G. Malanga et al., "Outcomes after ultrasound-guided platelet-rich plasma injections for chronic tendinopathy: a multicenter, retrospective review," $P M \ll R$, vol. 5, no. 3, pp. 169-175, 2013.

[85] N. J. Maxwell, M. B. Ryan, J. E. Taunton, J. H. Gillies, and A. D. Wong, "Sonographically guided intratendinous injection of hyperosmolar dextrose to treat chronic tendinosis of the Achilles tendon: a pilot study," AJR. American Journal of Roentgenology, vol. 189, no. 4, pp. W215-W220, 2007.
[86] M. Ryan, A. Wong, and J. Taunton, "Favorable outcomes after sonographically guided intratendinous injection of hyperosmolar dextrose for chronic insertional and midportion achilles tendinosis," American Journal of Roentgenology, vol. 194, no. 4, pp. 1047-1053, 2010.

[87] A. R. Bokhari and G. A. C. Murrell, "The role of nitric oxide in tendon healing," Journal of Shoulder and Elbow Surgery, vol. 21, no. 2, pp. 238-244, 2012.

[88] R. Osadnik, J. Redeker, R. Kraemer, P. M. Vogt, and K. Knobloch, "Microcirculatory effects of topical glyceryl trinitrate on the Achilles tendon microcirculation in patients with previous Achilles tendon rupture," Knee Surgery, Sports Traumatology, Arthroscopy, vol. 18, no. 7, pp. 977-981, 2010.

[89] J. A. Paoloni, R. C. Appleyard, J. Nelson, and G. A. C. Murrell, "Topical glyceryl trinitrate treatment of chronic noninsertional achilles tendinopathy. A randomized, double-blind, placebocontrolled trial," The Journal of Bone \& Joint Surgery-American Volume, vol. 86, no. 5, pp. 916-922, 2004.

[90] T. P. C. Kane, M. Ismail, and J. D. F. Calder, "Topical glyceryl trinitrate and noninsertional Achilles tendinopathy: a clinical and cellular investigation," The American Journal of Sports Medicine, vol. 36, no. 6, pp. 1160-1163, 2008.

[91] K. Knobloch, R. Grasemann, M. Spies, and P. M. Vogt, "Intermittent KoldBlue cryotherapy of 3x10 min changes mid-portion Achilles tendon microcirculation," British Journal of Sports Medicine, vol. 41, no. 6, article e4, 2007.

[92] K. Knobloch, R. Grasemann, M. Spies, and P. M. Vogt, "Midportion achilles tendon microcirculation after intermittent combined cryotherapy and compression compared with cryotherapy alone: a randomized trial," The American Journal of Sports Medicine, vol. 36, no. 11, pp. 2128-2138, 2008.

[93] P. Manias and D. Stasinopoulos, "A controlled clinical pilot trial to study the effectiveness of ice as a supplement to the exercise programme for the management of lateral elbow tendinopathy," British Journal of Sports Medicine, vol. 40, no. 1, pp. 81-85, 2006.

[94] B. Lind, L. Öhberg, and H. Alfredson, "Sclerosing polidocanol injections in mid-portion Achilles tendinosis: remaining good clinical results and decreased tendon thickness at 2-year followup," Knee Surgery, Sports Traumatology, Arthroscopy, vol. 14, no. 12, pp. 1327-1332, 2006.

[95] M. F. Joseph, K. Taft, M. Moskwa, and C. R. Denegar, "Deep friction massage to treat tendinopathy: a systematic review of a classic treatment in the face of a new paradigm of understanding," Journal of Sport Rehabilitation, vol. 21, no. 4, pp. 343-353, 2012.

[96] J. Orchard, A. Massey, J. Rimmer, J. Hofman, and R. Brown, "Delay of 6 weeks between aprotinin injections for tendinopathy reduces risk of allergic reaction," Journal of Science and Medicine in Sport, vol. 11, no. 5, pp. 473-480, 2008.

[97] R. Brown, J. Orchard, M. Kinchington, A. Hooper, and G. Nalder, "Aprotinin in the management of Achilles tendinopathy: a randomised controlled trial," British Journal of Sports Medicine, vol. 40, no. 3, pp. 275-279, 2006.

[98] N. Maffulli, F. Spiezia, U. G. Longo, V. Denaro, and G. D. Maffulli, "High volume image guided injections for the management of chronic tendinopathy of the main body of the Achilles tendon," Physical Therapy in Sport, vol. 14, no. 3, pp. 163-167, 2013.

[99] M. Paavola, S. Orava, J. Leppilahti, P. Kannus, and M. Järvinen, "Chronic achilles tendon overuse injury: complications after surgical treatment. An analysis of 432 consecutive patients," The 
American Journal of Sports Medicine, vol. 28, no. 1, pp. 77-82, 2000.

[100] R. Kearney and M. L. Costa, "Insertional achilles tendinopathy management: a systematic review," Foot and Ankle International, vol. 31, no. 8, pp. 689-694, 2010.

[101] J. I. Wiegerinck, G. M. Kerkhoffs, M. N. van Sterkenburg, I. N. Sierevelt, and C. N. van Dijk, "Treatment for insertional Achilles tendinopathy: a systematic review," Knee Surgery, Sports Traumatology, Arthroscopy, vol. 21, no. 6, pp. 1345-1355, 2013.

[102] M. J. DeOrio and M. E. Easley, "Surgical strategies: insertional achilles tendinopathy," Foot \& Ankle International, vol. 29, no. 5, pp. 542-550, 2008. 


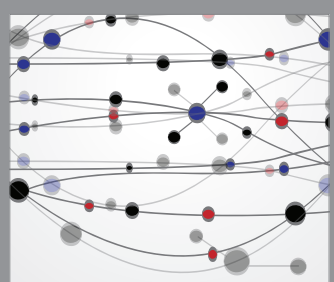

The Scientific World Journal
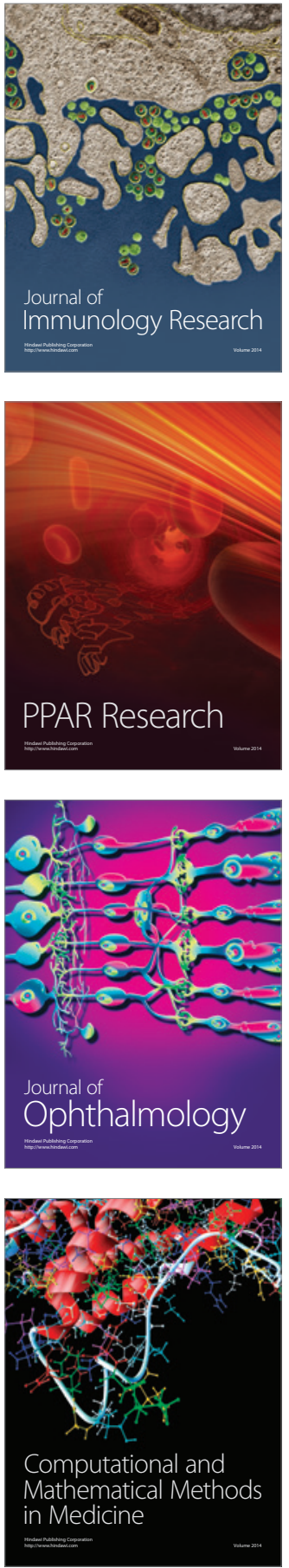

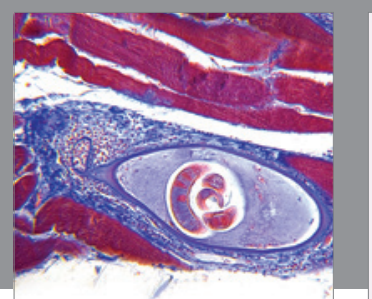

Gastroenterology Research and Practice

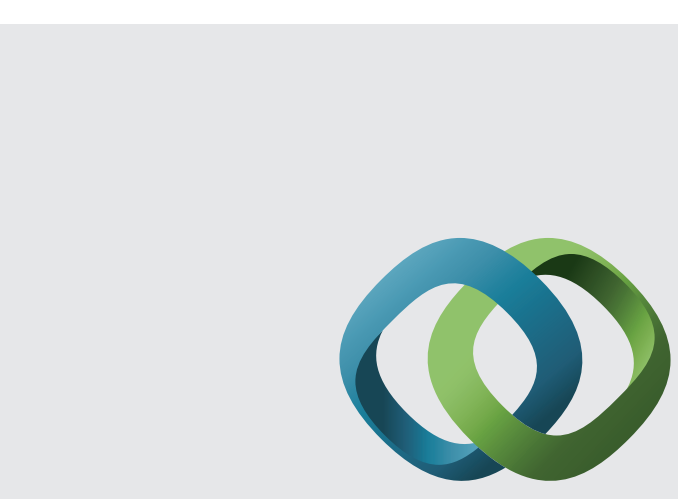

\section{Hindawi}

Submit your manuscripts at

http://www.hindawi.com
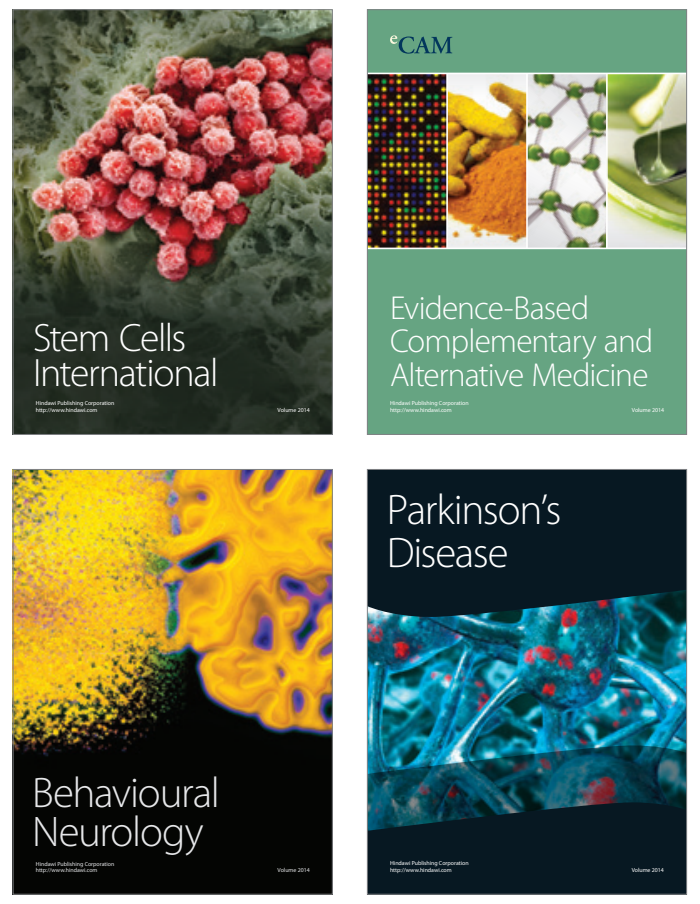
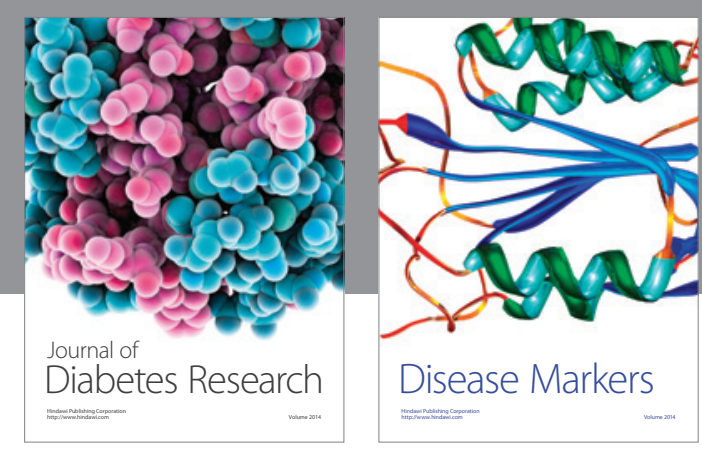

Disease Markers
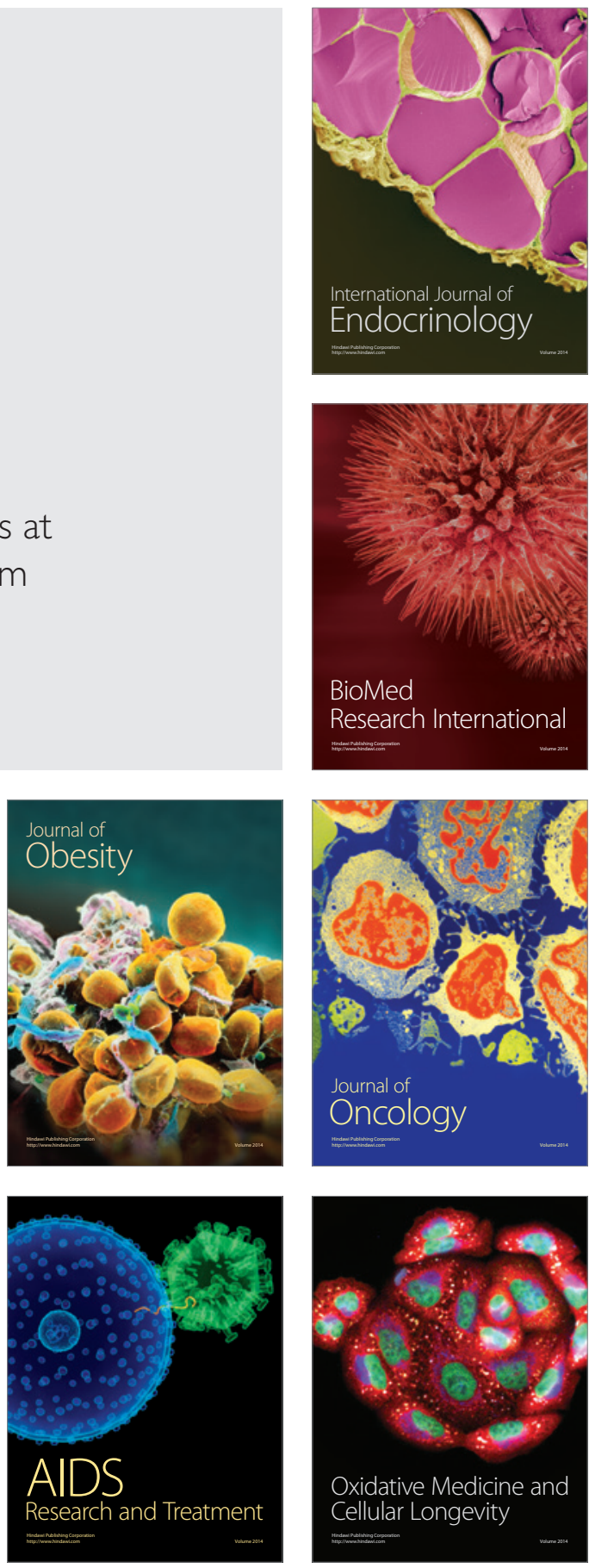